\title{
BUITE-KERKLIKHEID EN MAKRO-KERKLIKHEID IN DIE MODERNE EKKLESIOLOGIE
}

\author{
J.M. Vorster \\ Departement Ekklesiologie \\ HTS/PU vir CHO \\ HAMMANSKRAAL/POTCHEFSTROOM
}

\begin{abstract}
Two significant trends can be identified in the church of today: indifferentism and the emergence of a macro-church. Indifferentism bears the implicit meaning that the church is no longer neganded as being important or having significance for Christianity. In line with this thought it is claimed that it is possible to be a Christian without having any official commitment to a chunch as stucture. The term macro-church, on the other hand, describes the concept of the church as primarily being a huge ecumenical structure which acts as 'super church' in the world. These two trends should be regarded with caution. Not onty are these trends theologicalty questionable, but the imponance and effectiveness of the local church is also disregarded. When aiming to develop and establish the true essence of Christianity in future, the functioning of the local church should be restored. In this article it is thus angued that for the immediate future the main task of the Ecclesiology will be to establish the original meaning and functionality of the local chunch.
\end{abstract}

\section{INLEIDING}

Die Ekklesiologie as teologiese dissipline het die afgelope vyftig jaar besondere aandag ontvang. Saam met die lewendige diskussies oor die gesag van die Skrif, die Hermeneutiek en die teologiese Etiek is die fokus van teologiese en sosiologiese besinning baie skerp gerig op die kerk en die rol van kerke in 'n snel veranderende wêreld. Die skynbaar onophoudelike stroom publikasies oor die kerk uit teologiese en sosiologiese kringe, asook die groot navorsingsprojekte en aksieprogramme en ekumeniese liggame is 'n duidelike bewys van die nuwe groot belangstelling in die kerk.

Vanuit die verskillende konfessionele rigtings, gerugsteun deur ' $n$ kragtige inset van die Sosiologie en die Futurologie sien baie nuwe omskrywings, definisies en standpunte oor die kerk die lig. Nuwe ingrypende standpunte oor die wese en roeping van die kerk is in die afgelope paar dekades geformuleer. Hoekendijk (1966:22) het die proses ingelei deur teoloë te laat besin oor sy siening van die kerk as "the coming into being of a new mankind". Cox (1967:123) het veral die aktualiteit van die kerk in die proses van wêreldvernuwing beklemtoon met sy beskrywing van die kerk as die avant garde van 'n nuwe orde. Die kerk as werktuig in strukturele politieke bevryding het die gewilde tema in die Teologie van Bevryding geword (Moltmann 1967:338; Gutierrez 1974:223 
en Boesak 1979:25). In dieselfde denkklimaat het Fierro (1977:28) die kerkbeskouing van die Politieke Teologie saamgevat met sy beskrywing van die kerk as "an institutionalization of this criticism of society". Dit alles dui op 'n nuwe benadering tot die kerk. Hoewel hierdie beskouinge uiteenlopend is, poog dit om klem te lê op die sosiale rol en betekenis van die kerk in die moderne wêreld. In hierdie proses word radikaal weggebreek van die bekende tradisionele opvattings van die kerk.

In evangeliese kringe word ook herbesin oor die betekenis van die kerk. Teenoor die tradisionele gestalte van die kerk word gesoek na soepelheid en informaliteit as reaksie teen die 'rigiede' en 'formele' kerk-wees van die verlede. Die funksionering van die Deutsche Evangelischer Kirchentag met sy klem op die ervaring (Krause, 1989:8) en groot gewildheid onder die Duitse jeug is hiervan een sprekende voorbeeld. Die klem word gelê op massabetrokkendheid, ervaring, warmte en evangeliserende gerigtheid. Ook hier word nuwe modelle vir kerk-wees gesoek soos Louw (1990:222) aandui. Dit gaan in hierdie kringe nie soseer oor wêreldverandering en samelewingsverbetering nie, maar oor geestelike ervaring waaryoor die kerk primêr ingespan word.

Onderliggend aan hierdie uitsprake en definisies lê egter twee duidelike aanwysbare tendense. Dit is enersyds duidelik dat in die teologie afgereken word met die tradisionele opvatting van die kerk as ' $n$ instituut met vaste aanbiddingsvorme wat die uiterlike simbool van die Christendom as dominante kultuurstroming van die verlede was. Kerklikheid as betrokkendheid by die instituut is nie meer van belang nie en geld nie noodwendig meer as groeibodem vir godsdienstigheid nie (Coetzee, 1976:20). Hierdie tendens kan 'buite-kerklikheid' genoem word. Andersyds is daar ook die tendens van herbeklemtoning van die instituut, maar dan met 'n totaal nuwe funksie en gerigtheid. Hierdie tendens het reeds deurgeskemer in die enkele definisies uit die Teologie van Bevryding en die Politieke Teologie wat hierbo genoem is. In hierdie verband word kerk-wees gesien in die funksionering van die 'wêreldkerk' waarin kerke opgaan in groot ekumeniese liggame om as makro-instituut in wèreldpolitiek betrokke te wees. Hierdie tendens kan 'makro-kerklikheid' genoem word. Buite-kerklikheid en makro-kerklikheid kan gesien word as twee belangrike tendense in die huidige Ekklesiologie. Daarom word elkeen van die twee tendense vervolgens verder bespreek met besondere aandag aan die positiewe en negatiewe gevolge wat dit inhou vir die gereformeerde kerkopvatting en praktyk.

\section{BUITE-KERKLIKHEID}

Die Rooms-Katolieke godsdiens-sosioloog Schreuder (1969:27) vra oor die verhouding godsdienstigheid en kerklikheid die volgende vraag: 
Bloeit het geloof in de samenleving slechts dan, wanneer iedereen bij een kerkgenootschap of een levensbeschouwelijke vereniging is aangesloten, de godsdienstige en sociale dogma's ervan onderschrijft, de rituele en ctische normen zo nauwkeurig mogelijk vervult, eventueel nog lid wordt van een of ander bijzondere vereniging $c n$ wanneer men hom aanraadt om zich in dit kader voor de verbreiding en versterking van de institutic in te zetten?

Schreuder ag dus kerklike betrokkenheid en aktiwiteite in kerklik-institutêre bedrywighede nie as 'n noodwendige noodsaaklikheid vir geloof nie. Die mens kan hiervolgens, dus gelowig en godsdienstig wees sonder om kerklik te wees. 'n Mens moet in ag neem dat hy vanuit 'n Rooms-Katolieke belewingswêreld skryf en dan is dit des te meer insiggewend dat hy 'n neiging sien weg van die simboliese, die vormlike en die organisatoriese struktuur. Sy gewaarwording klop met die diagnose van Moltmann, 1967:305) waarin hy onder andere sê dat die kerk nie meer gesien word as die kroon van die Christelike samelewing nie.

Hierdie tendens word onder woorde gebring met die vraag of die Christelike godsdiens nog die kerk nodig het. Met 'kerk' in hierdie vraag word nie die Bybelse ideaal-tipiese omskrywing van die kerk bedoel nie, maar die kerk as tradisie, as oorgegewenheid uit 'n vorige kultuurperiode. Hiermee word bedoel dat die kerk daar uitsien soos dit deur die geskiedenis verpak is in ' $n$ ideologiese omhulsel en beïnvloed is deur tydsgebreke, kultuur- en omgewingsinvloede. Volgens hierdie siening is die kerk' $n$ historiese werklikheid; 'n groot struktuur met baie simbole, rituele, tradisionele uitsprake en vorme wat al hoe minder verstaanbaar word. Die sosioloog Dekker (1971:20-21) tipeer die kerk in hierdie verband treffend in sy beskrywing van die Europese gestalte van die kerk. Die kerk, so gedefinieer, het as instituut irrelevant geword. Mense voel hulle daarby nie meer betrokke nie. Rootmensen (1990:29) sề hieroor dat geloof en kerk aparte 'deelgebiede' geword het. Volgens hom is kerkverlating nie die gevolg van sekularisasie nie, maar het te doen met die 'misbaarheid' en selfs 'ongeloofwaardigheid' van die instituut. In hoeverre kan die Christelike geloof nog institusioneel in hierdie produk van die geskiedenis veranker word? Dit is die vraag wat baie aktueel geword het in die hedendaagse Ekklesiologie. Die algemene tendens is om hierdie sosiologiese werklikheid teologies te akkommodeer deur die hele konsep van die kerk as instituut te bevraagteken. Die Teologie het saam met die Sosiologie begin meewerk aan die devaluering van die instituut. Enkele voorbeelde kan genoem word:

\section{Die Apostolaatsteologie}

Die Apostolaatsteologie het in Protestantse kringe die sogenaamde institusionalisme van die kerk onder die vergrootglas geplaas en 'n nuwe weg probeer aandui. Duvenage (1962:168-177) gee hiervan 'n duidelike uiteensetting. Hy wys aan hoe, veral by Kraemer en Van Ruler, die kerk gesien is as 'n 'missiologiese instituut' waarin die 
struktuur deur die funksie bepaal word. Die roeping gaan die wese van die kerk vooraf. Volgens die Apostolaatsteologie kan die kerk nooit vasgele word in 'n struktuur met kenbare 'uitwendige' vorme nie. Omdat die funksie voorafgaan, is die kerk in wese veranderlik: dit is die altyd 'wordende' en 'groeiende' kerk. Die kerk word dus geïdentifiseer met die Christendom as stroming wat in die wêreld uitdy in al groter-wordende sirkels.

In hierdie verband moet ook gewys word na die invloed van Hoekendijk wat in sy artikels, wat van 1948 tot 1964 verskyn het, die institusionalisme van die kerk sterk afgewys het. Vir hom was die roeping van die kerk veel belangriker as die uitwendige vorm en die merktekens. Sy kritiek teen die bestaande kerk is dat kerke geslote kringe geword het wat hulle net bepaal by sekere klasse in die samelewing. In sy tyd het Hoekendijk dit byvoorbeeld as onsinnig beskou om die kerk in sy verouderde struktuur tot evangelisasie op te roep, voordat die kerk struktureel radikaal en rewolusionêr verander word. Die kerk kan alleen doeltreffend wees as hy ' $n$ funksie word van die 'apostolaat'. Hoekendijk (1966:22) is dan ook van mening dat die formule Credo ecclesiam apostolicam beteken: "I believe in the church which is the function of the apostolate, that is an instrument of God's redemptive action in this world." Uiteindelik kan die kerk dus nie 'n struktureel kenbare geïnstitusionaliseerde religious community wees nie, maar 'n beweging wat geken word aan sy sosiale dade.

Dit is opmerklik hoe Schreuder se sosiologiese oplossing vir die toenemende irrelevansie van die kerklike instituut by die teologiese oplossings van die Apostolaatsteologie hieroor aansluit. Hy sè dat die Christelike geloof 'n onsigbare grootheid moet wees wat in die wèreld aanwesig is en dat dit nie tot vergestalting hoef te kom in ' $n$ sigbare kerklike instituut nie (Schreuder, 1969:7). Buite-kerklikheid is nie noodwendig ongeloof nie. Ons moet, volgens hom, nie al te ligvaardig praat oor geloofsverlies en sekularisasie wanneer die agteruitgang van kerklidmaatskap bereken word nie. Die moderne mens kan "zich eenvoudig niet volledig aan een institutie wijden". Die kerk moet afsien van sy rasionele leer en uitwendige stempel. Dit is uiteindelik net tydsgebonde. Die kerk kan hoogstens as instituut funksioneer om 'outentieke geloof' moontlik te maak en te 'stimuleer'.

\section{2 'Kerk buite die kerk'}

Die teologiese hantering van die tendens van buite-kerklikheid het verder verloop in die prinsipiële aanvaarding van die konsep kerk buite die kerk. Daarmee word bedoel dat kerk bestaan buite die gevestigde kerke. Anders gestel: sonder om kerklik verbonde te wees, kan 'n gelowige bloot in sy (buite-kerklike) bestaan deel wees van die kerk van Christus. Vir Christen-wees is die bestaande kerklike instituut nie nodig nie. Die 
konsep kerk-buite-die-kerk is volgens Matthes (1969:30) nie die produk van teologiese besinning nie. Dit spruit uit die belewenis van die 'kerkvolk', in sowel RoomsKatolieke as Protestantse kringe. Veral Sölle het, soos die Apostolaatsteologie, die werklikheid teologies aanvaarbaar probeer maak.

Sölle wil die bestaan van die kerk verklaar vanuit die heil van die wêreld. Onder heil moet verstaan word die geregtigheid en vrede in politieke sin. Waar heil is, daar is die kerk. Jesus en sy liefue kan nie in die gevestigde kerk gelokaliseer word nie, maar die kerk moet gesoek word waar Jesus en sy liefde is (Sölle, 1972:75). Ook buite die kerk is kerk. Sy noem dit die "latente kerk". In haar betoog oor die waarheid wat konkreet moet wees, oefen sy skerp kritiek uit op die geïnstitusionaliseerde kerk wat by mense die veronderstelling skep dat "zij de mensen tot zichzelf, tot de gemeente met haar eigen levenstijl en religiositeitsstructuur moet bekeren" (Sölle, 1967:117). Die kerk kan dus nooit 'n instituut wees wat dien as kragstasie van liefde en geregtigheid nie maar verteenwoordig eerder die effek, die gevolg, die uitwerking van Jesus van Nasaret en sy liefde in die wêreld.

\section{3 "Distanzierte Kirchlichkeit"}

Scholten (1969:30) hanteer die tendens van buite-kerklikheid met sy begrip van "distanzierte Kirchlichkeit". Hy baseer sy oortuiging openlik op sosiologiese bevindinge en wil vanuit daardie hoek 'n weg vir moderne kerkwees aandui. Volgens hom hoef kerklike deelname nie altyd direk, vanuit die instituut, te wees nie. Die tyd van direkte deelname (byvoorbeeld erediens en kerkbesoek) was funksioneel in die vorige eeu, maar dit kan in die veranderde verhouding van kerk tot samelewing nie meer geld nie. Die moderne Christen se deelname aan die kerk is insidenteel of dit kan selfs totaal ontbreek.

In dieselfde boek gee Scholten interessante resultate van 'n gevalle-studie weer. Aan 'n groep kerklike mense en 'n groep buite-kerklike mense is vrae gevra oor temas soos die bestaan van God, Christus, die hiernamaals en ander temas uit die geloofsleer. Uit die antwoorde wat gegee is, lei Scholten af dat daar ongeloof binne die kerk is en geloof buite die kerk. Buite-kerklikes het dus die geloofsleer aanvaar terwyl kerklikes bedenkinge uitgespreek het oor die bestaan van God, Christus ensovoorts. Daar is dus gelowiges sonder enige kerklike verbintenis en 'kerkmense' wat nie werklik glo nie, maar tog lid wil wees van 'n kerklike instituut.

Buite-kerklikheid as tendens in die hedendaagse Christendom is dus duidelik deur die Sosiologie geïdentifiseer en deur die Teologie op wye vlak geakkommodeer. Buitekerklikheid as ekklesiologiese tendens berus dus daarop dat die moderne Christen 
hom nie meer aan die kerklike instituut kan (sosiologies) of hoef (teologies) te wy nie. Die moderne Christen het, volgens moderne sosioloë en verskeie teoloë, die ruimte en, die reg op ywer vir breë Christelik-georiënteerde deelname in die wêreld buite die gevestigde kerk om.

Die tendens is duidelik in Suid-Afrika sigbaar. Bewegings sonder die kerklike instituut, soos Youth for Christ en die Pinksterbeweging, groei terwyl die lidmaatgetalle van gevestigde kerke daal. Oor die algemeen daal bywoning van eredienste, neem finansiële bydraes af en is al hoe minder mense beskikbaar vir besondere dienste in kerke. Hoewel die grootste hoeveelheid van die Suid-Afrikaanse bevolking hulle identifiseer as Christene, toon kerklik-institutêre betrokkenheid van Christene in SuidAfrika 'n groeiende afname. Wat in die sestiger en sewentigerjare in Europa afgespeel het, vind nou in Suid-Afrika plaas. Die groei van 'n 'buite-kerklike Christendom' is duidelik vir elkeen om te sien.

\section{MAKRO-KERKLIKHEID}

Die huidige tendens van makro-kerklikheid is 'n negatiewe vrug van die ekumeniese beweging wat beskou kan word as die belangrikste gebeurtenis in die kontemporère kerkgeskiedenis. Die strewe na 'n duidelike vergestalting van die kerk se ekumeniese roeping is 'n positiewe ontwikkeling - juis binne die kerklike konteks waarin die beweging posgevat het. Tog het hierdie ontwikkeling die verskynsel van 'makrokerklikheid' tot gevolg gehad en kan hierdie een uitvloeisel van die ekumeniese beweging met ernstige kritiek bejeën word.

Reeds vroeg gedurende hierdie eeu het die gedagte posgevat dat die kerke sal moet soek na groter eenheid ten einde gesamentlik die groot taak ten opsigte van sending aan te pak. Visser 't Hooft (1970:3-4) wat in die beweging 'n belangrike rol gespeel het, onderskei drie periodes in die ekumeniese beweging. Die eerste fase het geduur van 1910-1935 en hy noem dit die fase van die pioniers wat die ekumeniese strewe sterk gesteun het en sodoende die kerke opnuut bewus gemaak het van die ekumene. Reeds gedurende hierdie tydperk het allerlei bewegings ontstaan waarvan die Life and Work- en Faith and Order-bewegings die bekendstes was. Die tweede fase het geduur van 1935-1948. Dit was die periode van die 'argitekte' wat wou poog om 'n duideliker beeld van die ekumene daar te stel. Hierna het in 1948 die derde periode begin met die stigting van die Wêreldraad van Kerke (WRK) as 'n oorkoepelende kerklike liggaam waardeur kerke 'n ekumeniese en missionêre roeping kon vervul. Die basisformule van die WRK lui soos volg:

The WCC is a fellowship of churches which accept our Lord Jesus Christ as God and Saviour 
according to the Scriptures and therefore seek to fulfil together their common calling to the glory of one God, Father, Sun and Holy Spirit." (WRK, 1961:2).

Die ekumeniese beweging wou'n nuwe effektiewe vorm van kerk-wees vergestalt. Ook uit reaksie teen die institusionalisme en formalisme van die kerk in die vorige eeu is met die beweging gepoog om die kerk effektief en funksioneel te maak vir 'n nuwe wêreld met besondere uitdagings. Die kerk moes veral funksioneel word vir die eenheid van die mensdom. Die WRK het hierdie rol vervul. Hoewel die Sentrale Komitee in 1950 verklaar het dat die liggaam nie 'n superkerk wil wees nie, maar'n koördinerende liggaam tussen kerke (WRK, 1954), het hy reeds vroeg in sy bestaan die rol begin speel van makro-kerk wat alle hindernisse in die weg van die brotherhood van die mensdom moet bestry (Vorster, 1981:58).

Die WRK as makro-kerk met 'n transformerende rol in die samelewing het sedert 1966 duidelik vorm begin aanneem. Die bekende kongres oor Kerk en Samelewing in Genéve het 'n heel nuwe siening oor die kerk en sy rol die lig laat sien. Dit is belangrik om daarop te let dat die rol van die kerk nie teologies gedefinieer is nie, maar omskryf is vanuit die sosiologiese analise van die moderne samelewing. Die wese en roeping van die kerk is aangepas om die eise van die samelewing te beantwoord. Onder leiding van Shaull (1968:20) is die moderne wêreld eers ondersoek met behulp van die sosiale analise van die neo-Marxisme. Vanuit hierdie ideologiese hoek het Shaull tot die konklusie gekom dat die moderne gemeenskap 'n verslawende gemeenskap is. Die mens se vryheid tot geluksbelewing word aan bande gelê deur 'verdrukkende' politieke strukture. Daaruit moet die mens bevry word (Vorster, 1981:104).

Bevryding het die sleutel geword waarmee 'n nuwe vrye wêreld vir die verslaafde mens oopgesluit kan word en hierin het Shaull die geleentheid vir die kerk gesien. Om weer relevant te wees, moet die kerk strukturele bevryding ondersteun en oral bevorder om waarlik betekenis vir die wêreld te hê. Op rewolusionêre wyse moet die kerk betrokke raak by wêreldpolitiek en ekonomie. Shaull se beskouing is uitgewerk in sy voorstel van 'n Teologie van Rewolusie en dié teologie het die program geword van die WRK soos die liggaam dit self stel in sy weergawe van die 1966 kongres:

As Christians wc are committed to work for the transformation of society. In the past we have usually done this through quiet efforts at social renewal, working in and through the established institutions according to their rules. Today, a significant number of those who are dedicated to the service of Christ and their neighbour assume a more radical or revolutionary position (WRK, 1967:49).

Die WRK het begin funksioneer as 'n makro-kerk. Deur sy Programme to combat racism (PCR) (WRK, 1971:173) het hy die politieke arena betree en met direkte steun aan verskeie bevrydingsbewegings die proses van radikale politieke bevryding in 
verskeie wêrelddele bevorder. As super kerklike liggaam het die WRK sedert 1966 allerlei aksies geloods met die oog op die bestryding van alles wat die brotherhood van die wêreldgemeenskap sou verhinder. Voortvloeiend uit die ekumeniese beweging het die WRK dus na vore gekom as 'n makro-kerk wat op die basis van die politieke teologie die middel wou wees tot wêreldvernuwing.

Die ekumeniese beweging met die WRK as uiteindelike vrug het die tendens van makro-kerklikheid bevorder. Hierin word die kerk dan gesien as 'n werreldwye superstruktuur wat sy rol geheel en al vind in sosiale aksies. Anders as in die vorige eeu word die kerk gesien as 'n kragtige universele middel tot die doel van wêreldvernuwing deur politieke bevryding. Die fokus word heeltemal verskuif van die plaaslike kerk en evangelisering na 'n superkerk en sosiale transformering.

Makro-kerklikheid het in die Ekklesiologie aansteeklik gewerk. Ekumeniese strukture het nuwe aandag ontvang. Kerk-wees het tot 'n groot mate begin opgaan in streeksliggame soos die Britse Raad van Kerke, World Alliance of Reformed Churches en in Suid-Afrika die Suid-Afrikaanse Raad van Kerke. Die standpunte van ekumeniese liggame het die 'stem van die kerk' geword. Die kerk word as 'n korporatiewe grootheid gedefinieer wat byvoorbeeld as verenigende faktor die sosiale versoening in 'n gepolariseerde gemeenskap tot stand moet bring (vgl. byvoorbeeld Deist, 1989:894).

Op hierdie wyse het daar drastiese wysiginge ingetree in die beskouinge oor die wese en roeping van die kerk. Die wese van die kerk word primêr uitgedruk in die oorkoepelende struktuur, met die sekretaris-generaal of sentrale komitee as mondstuk. Ekumeniese vergaderings, kerklike konferensies en sinodes het belangrik geword. Die aktiwiteite van die plaaslike kerk het ondergeskik geraak aan die aksies van die makrokerke. Gevolglik het die kerklike belewenis van die gelowige vervaag: hy ervaar kerkwees as iets buite homself wat daar ver (en hoog) afspeel in die groot vergaderings van die makro-kerk. Hoewel die makro-kerk sy stem hoorbaar maak op die sosiale erf het dit, net soos die tendens van buite-kerklikheid, bygedra tot die devaluasie en irrelevansie van die plaaslike kerk. So het die ekumeniese beweging met alles wat positief daaroor gesê kan word, tog bygedra tot die tendens van makro-kerklikheid.

\section{REFORMASIE OF DEFORMASIE ?}

Hoe moet hierdie twee belangrike ekklesiologiese tendense beoordeel word? Moet die ontwikkelinge beskou word as reformasie of deformasie? Kan hieruit iets goeds voortkom om die kerk meer betekenis te gee vir die jaar 2000? Hierdie vrae moet versigtig beantwoord word, veral as rekening gehou word met die feit dat die veranderinge in kerkbeskouing nie soseer net nuwe teologiese denke is nie, maar teologiese 
akkommodasie van sosiale veranderinge. Die volgende kritiese en waarderende opmerkings mag van waarde wees.

\subsection{Die bydrae en bedreiging van buite-kerklikheid}

Die mees voor die hand liggende kritiek teen die tendens van buite-kerklikheid is dat die dieper Bybelse betekenis van die kerk soos uitgedruk met die beeld "liggaam van Christus" (1 Kor. 12:27; Ef. 4:12; Kol. 1:18) verlore gaan. Christus is die hoof en sy liggaam is die gemeente. Die hoof (kop) is organies aan die liggaam verbind. Die liggaam word deur die hoof in beweging gebring. Buite die liggaam kan die ledemaat nie aan die hoof verbind wees nie. Christus se verbintenis aan sy gemeente is lewend en organies. Deur die hoof is die ledemate aan mekaar verbind. Die plaaslike gemeente is die volledige openbaring van die liggaam van Christus in sy volle betekenis. Al die eienskappe van die liggaam kom in die plaaslike kerk na vore. Verbondenheid aan Christus kan nie bestaan buite die kerk om nie. 'n Gelowige kan nie aan die hoof verbind wees as hy nie aan die liggaam, soos sigbaar uitgedruk in die plaaslike kerk, verbind is nie. Küng (1967:264) sề hieroor:

... omdat de gelovigen in de doop door de ene Geest zjnn ingelijft in het lichaam van Christus; omdat zij door de maaltijd verenigd zijn tot een lichaam daarom behoren zij in het leven van alledag te leven als ledematen van het ene lichaam en de eenheid van het ene lichaam te verwerkelijken.

Ridderbos (1971:438-441) gee dieselfde verklaring van die uitdrukking. Wie hom losmaak van die kerk, maak hom los van Christus.

Die groeiende tendens van 'n buite-kerklike Christendom of godsdienstigheid waarin die kerk nie funksioneer nie moet dus prinsipieel afgewys word. So 'n verskynsel kan nie teologies geakkommodeer word nie. Die tendens moet ook gesien word as 'n bedreiging vir die gelowige. Die ignorering van die plaaslike kerk ontneem die gelowige van die geloofsopbou van prediking, sakramentsbediening en geloofsgemeenskap. Die gedagte dat hy Christen kan wees sonder om kerklik te wees, weerhou hom van sy roeping tot offervaardigheid en betrokkenheid by ander. Algaande moet die tendens van buite-kerklikheid die Christendom van sy uniekheid beroof en sal dit dien as 'n tussenstap tot 'n post-Christelike kultuur.

Buite-kerklikheid het wel 'n boodskap vir die kerk. Waarom het die tendens ontstaan? Wat is die redes vir die gedagte dat die Christelike godsdiens nie meer die kerk nodig het nie? Sosioloe sal vele redes kan aandui. Hier word volstaan met die belangrikste rede: buite-kerklikheid is onder andere ' $n$ reaksie teen kerklike institusionalisme en dooie formalisme. Institusionalisme bestaan wanneer die kerk doel op sigself word en 
nie ' $n$ middel tot 'n doel nie. Dit is wanneer die gelowige kerklidmaatskap sien as die doel van Christen-wees en nie as middel waardeur sy Christen-wees in die wêreld en sy geloofsekerheid versterk word nie. Daar lê baie openlike institusionalisme in die gereformeerde bediening. Prediking wat die gelowige slegs oproep tot beter kerklike betrokkenheid, en katkisasie en huisbesoek wat slegs die gehalte van kerklidmaatskap bevorder, is, soos buite-kerklikheid, deformasie van die kerk.

Formalisme word aangewakker deur bediening wat slegs ou vorme in stand hou sonder die inhoud of prinsipiële grondslag. Mense verstaan nie meer waarom dit gaan nie. Dikwels word die vorm self verhef tot die beginsel. So word die kerk 'n koue museum van vorme en gebruike waarin die moderne gelowige nie meer belang het nie. Hy gaan soek dan sy heil in Christus, buite die kerk.

Die bestryding van buite-kerklikheid gaan daarom nie lê in institusionalisme nie. Myns insiens moet dit eerder gesoek word in die beginsel dat die kerk nie doel op sigself is nie, maar middel tot 'n doel. Graafland (1987:100) bting die beginsel mooi onder die aandag wanneer hy sê: "... de kerk is primair een functioneel gebeuren van het Woord". Die kerk moet funksioneel wees - funksioneel in die koms van die koninkryk. Daarom moet die bediening nie net ou vorme in stand hou of die kerk as instituut adverteer en verkoop nie, maar dit moet die gelowige toerus om die koninkryk van God in sy lewe en werke te laat gestalte kry. Dit op sigself vereis reformasie. Die hedendaagse neiging om buite-kerklikheid met institusionalisme te bestry, lê diep gewortel. Dit hou die kerk in die bose kringloop van kerkverval. Slegs funksionele koninkryksbediening gaan hierdie sirkel deurbreek. Die pleidooie vir koninkryksbediening soos byvoorbeeld deur Spoelstra (1989:5) en Baarlink (1990:65) behoort daarom ernstig bejeën te word.

\subsection{Die bydrae en bedreiging van makro-kerklikheid}

Die ekumeniese beweging het ook gegroei uit die gees van die tyd. Die verskeurdheid van kerke in die vorige eeu het die Christelike getuienis in die wêreld benadeel. Die behoefte aan groter eenheid in getuienis is veral op die sendingveld gevoel. Dit moet dus waardeer word dat die ekumeniese beweging in die eerste dekades van hierdie eeu die bewustheid tot sending gestimuleer het. Byna al die ekumeniese liggame wat uit die ekumeniese beweging ontstaan het, het die sendingroeping sterk ondersteun en nuwe sendingmetodiek vir die kerke in die wêreld uitgewerk. In hulle onderskeie nuwe ekumeniese verbintenisse het kerke in die Derde Wêreld, met hulp van buite groot groei begin toon sodat dit een van die kenmerke van die twintigste-eeuse kerkgeskiedenis geword het. . 
Tweedens moet die bydrae van die ekumeniese beweging tot die Christelike etiek en diakonaat hoog op prys gestel word. Berkhof (1967:298) toon dit oortuigend aan. Benewens skerp kritiek teen die Nasionaal-Sosialisme, rassisme, Kommunisme en verdrukking van minderheidsgroepe het groot diakonale projekte die lig gesien. Die opkoms van die wêrelddiakonaat het Christelike barmhartigheid meer effektief laat funksioneer. Dan kan ook waarderend verwys word na die positiewe bydrae van die ekumeniese beweging tot teologiese opleiding en toerusting.

Die vrugte van die ekumeniese beweging hou egter ook bedreiginge in. Hier kan veral verwys word na die Wêreldraad van Kerke. Hoewel die organisasie ook bygedra het tot van die positiewe ontwikkelinge wat hier bo genoem is, het sy skadukant na vore gekom in sy ideologiese kompromieë en bevordering van geweld onder 'n Christelike vaandel. Hierdie negatiewe sy van die ekumeniese beweging is reeds elders breedvoerig beskryf en beoordeel (Vorster 1981:58 e.v.). Benewens bogenoemde positiewe en negatiewe gevolge moet die ekumeniese beweging se bevordering van makro-kerklikheid as die grootste huidige bedreiging van die kerk aangestip word.

Die opkoms van makro-kerklike strukture het algaande die plaaslike kerk verdring. Dic belang van die prediking van die Woord, sakramentsbediening, pastorale werk en plaaslike diakonale verantwoordelikheid word oorskadu deur ekumeniese uitsprake en sentrale dienste. Vir die gelowige voel dit of hy van die kerk geskei word. Hy ervaar kerk-wees as iets buite en ver van hom af wat afspeel in die ekumeniese raad of sinode. Spoelstra (1989:7 en 344) wys die negatiewe gevolge hiervan in die kerklike lewe oortuigend aan. 'n Nuwe institusionalisme word geskep waarin plaaslike bediening drasties afgeskaal word.

Sonder om die ekumeniese roeping van die kerk te verskraal en die positiewe bydrae van die ekumeniese beweging te ontken, moet die bedreiging van makro-kerklikheid aangespreek word. En dit kan effektief gedoen word deur die plaaslike kerk opnuut na waarde te skat en te ontwikkel. Die nuwe wêreldwye beklemtoning van die konsep gemeentebou waarin die 'plaaslike bediening' weer meer aandag kry, is reeds 'n positiewe reformatoriese ontwikkeling (vgl. Noordegraaf 1990:123-145).

Buite-kerklikheid en makro-kerklikheid is die twee groot tendense in die moderne Ekklesiologie. Ter wille van kerklike effektiwiteit sal die Ekklesiologie die aandag toenemend moet rig op die plaaslike kerk, wat die middel moet wees tot die realisering van die tekens van die koninkryk. Dit sal die uitdaging wees vir die reformasie in die een-en-twintigste eeu. 


\section{BIBLIOGRAFIE}

BAARLINK, H. 1990. Blijvende aandag voor het Koninkrijk van God. Gereformeerd Teologisch Tijdschnifh 90(2):65-83.

BERKHOF, H. \& DE JONG, OJ. 1967. Geschiedenis der Kerk. Nijkerk : Callenbach.

BOESAK, A. 1979. The Black Church and the future. Ecunews. 24:19 e.v. (Ook opgeneem in The Ecumenical Review 1980 32:16-32 onder die (itel: The Black Church and the struggle in South Africa.)

COETZEE, J.K. 1976. Die sosiologiese verband tussen godsdienstigheid en kerklikheid : NGTT 17(1):2034 Januarie.

COX, H. 1967. De stad van de mens, het levenspatroon van de moderne wereld in theologisch perspectief. Utrecht : Ambo bocken.

DEIST, F.E. 1989. Die kerk: 'n Verenigende of verdelende faktor in dic ontwikkeling van Suid-Afrika. Hervormde Teologiese Studies 45(4):894-915. Nov.

DEKKER, G. 1971. Wat is er met de Kerk aan de Hand? Over de positic en funksie van de kerk in de huidige samenleving. Kampen : Kok.

DUVENAGE, S.C.W. 1962. Kerk, volk en jeug. Die verhouding van Kerk tot volk. Zaandijk : Heijnis.

FIERRO, A. 1977. The militant Gospel. An analysis of contemporary political theologies. London : S.C.M Press. (Oorspronklike titel: El evangelio beligeran te).

GRAAFLAND, C. 1987. Bijbel en belijdenis over de kerk. Radix, 13(3):95-107. Julie.

GUTIERRREZ, G. 1974. Theologie van de beviijding. Baarn : Ten Have.

HOEKENDUK, J.C. 1966 . The church inside out. London : S.C.M. Press.

KRAUSE, C. e.a. 1989. Unsere Zeit in Gottes Händen - Programm Deutscher Evangelischer Kirchentag 7-11 Juni 1989 in Berlin : Berlyn DEK.

KüNG, H. 1967. De Kerk. Antwerpen/Hilversum : Paul Brand.

LOUW, DJ. 1990. Charisma en amp. Op soek na koinoniale diensmodel vir gemeentebou. NGTT, 31(1):220-239. Junie.

MATTHES, J. 1969. Herkomst en sociale achtergrond van de uitdrukking kerk buiten de kerk. (In Goddijn, H.P.M. e.a. Kerk buiten de kerk, gesprekken van sociologen over kerkvernieuwing. Terzake IV. Baarn : Bosch en Keuning. p. 30.)

MOLTMANN, J. 1967. Theology of hope. London : S.C.M. Press.

NOORDEGRAAF, A. 1990. Overwegingen rondom het thema gemeenteopbouw. Theologia Refomata, 33(2):123-145. Junie.

RIDDERBOS, H. 1971. Paulus. Ontwerp van zijn theology. Kampen : J.H. Kok.

ROOTMENSEN, B.H. 1990. Secularisatie: Bevrijding of bedreiging? Radix, 16(1):25-32. Jan.

SCHOLTEN, R.G. 1969. Gedistantieerde kerkelijkheid; de probleme van kerkelijke declname en nietdeelname. (In Goddijn, H.P.M. c.a. Kerk buiten te kerk, gesprekken van sociologen en theologen over kerkvernieuwing. Terzake IV. Baarn : Bosch en Keuning.)

SCHREUDER, O. 1969. Gedaanteverandering van de kerk. Aanbevelingen voor vernieuwing. Nijwegen/Utrecht : Dekker en van de Vegt NV.

SHAULL, R. 1968. Revolutionaire veranderingen in theologische perspectief. (In Wereldraad van Kerke, Kerk en Revolutie, een bloemlezing uit de voorstudies voor het congres van de W.R.K. over kerk en Maatschappij. Baarn : Bosch en Keuning. p. 23-28).

SóLLE, D. 1967. De waarheid is concreet. Amsterdam : Ten Have.

SólLLE, D. 1972. Politieke theologie, dicussie met Rudolf Bultmann. Baarn : Bosch \& Keuning.

SPOELSTRA, B. 1989. Gereformeerde kerkreg en Kerkregering 'n Handboek by die kerkorde. Hammanskraal. HTS. 489 p.

VISSER 'T HOOFT, W.A. 1970. The general ecumenical development. (In Fey, H.E. e.a. The ecumenical advance, a history of the ecumenical movement, Vol. 2. London : S.P.C.K.)

VORSTER, J.M. 1981. Die kerk en'die kleurvraagstuk vandag. Johannesburg : De Jongh Uitgewers. 
WêRELDRAAD VAN KERKE. 1954. The first six years, a report of the Central Committee of the W.C.C. on the activities of the Departments and Secretariats of the Council. Geneve : W.R.K.

WéRELDRAAD VAN KERKE. 1961. Constitution and rules of the W.C.C. Genève : W.R.K.

WêRELDRAAD VAN KERKE. 1967. Christians in the technical and social revolutions of our time. World conference on church and society. Genève Julie 12-26. 1966. The official report. Geneve. W.R.K.

WéRELDRAAD VAN KERKE. 1971 Programme to combal racism. The Ecumenicaal Review, 23(2):173 e.v. April.

WRK

kyk

WERELDRAAD VAN KERKE 
